\title{
Exploring Religiosity and Psychological Wellbeing: The Relevance to Organizational Progress and Individual Development
}

\author{
Derrick Opoku Danquah \\ University of Electronic Science and Technology of China \\ School of Public Affairs and Administration
}

\begin{abstract}
Religion plays a pivotal role in most spheres of life. Religion has been directly linked to the foundation of psychotherapy, national legislations, institutional policies, organizational values, missions and work ethics. Religion tends to influence behavior and attitudes at the level of organizations demonstrable in this study from the context of Ghana. The study reviewed literatures on religious faith with some focus on workplace context and on individuals by investigating possible relationships between religious beliefs and practices on psychological wellbeing. Plethora of studies has established religion impact on enhancing individual capacity to ward off psychological strains. The evidence suggested by studies on the impact of religiosity on psychological wellbeing has implications for individuals, international and local organizations to incorporate elements of religious faith and practices for institutional progress and personal development. However, the benefits of religion to organizations necessitate further investigation to explore the various dimensions that can promote organizational growth.
\end{abstract}

Keywords: Religiosity, Psychological Wellbeing, Religion, Work Setting, Ghana, Attachment.

1.1Religion as a discipline has attracted minimal research attention in contrast to other many social science disciplines despite its potency in dealing and managing with mental health, behavioral deficits, stressors and provision of general understanding of life. Exemplary study by Laird, Marks, and Marrero (2011) on religiosity as a preventive measure demonstrated by showing a relationship between positive religiosity and lower occurrence of deviant behaviors in adolescences. Religion forms central to many tenets of life. 'Numerous researchers have identified religious belief as a potent force in society (e.g., Abdel-Khalek, 2010; McCullough \& Willoughboy, 2009). For example, researchers have discovered that religious belief influences self-control (McCullough \& Willoughboy, 2009), subjective well-being (Abdel-Khalek, 2010), job satisfaction (Kutcher, Bragger, RodriguezSrednicki, \& Masco, 2010), economic output (Stiner, Leinert, \& Frey, 2010), and happiness (French \& Joseph, 1999; Steiner, Liner, \& Frey, 2010)', quoted from Ivy (2014). It is however essential to divert adequate attention and resources to explore this field due it unrealized contributions to human growth and development.

The effect of religion in our life cannot be discounted, the effects of religion is practically inevitable on a daily basis (Weber, 2012). Individual's inclination to religious beliefs and faith serves as bedrock to dealing with stressors in life. Individuals with fervent religious inclination or strong religious faith have most of their actions based on beliefs and directions of decisions dictated by their religious doctrines. It qualify to reason that our daily life stressors are reflected and addressed with a coping mechanism in the doctrines of the religion one associates with which serves as a point of reference. Weber (2012) disclosed that it still seems appropriate to infer religiosity can provide a better coping mechanism in times of heightened distress due to its negative relationship to depression.

Such a vibrant tool has received less attention from researchers despite it supports in dealing with depression, stress and other psychological traumas. A critical survey of the various sacred doctrines revealed that there are codes of conducts and thoughts patterns speculated in different situations or context. Practitioners therefore ascribe to these codes in their assessment and dealing with life stressors and other life related issues. It is highly relevant that the study of religiosity should be encouraged and promoted since the perceived benefits are unacknowledged or underrated and therefore, it is essential the impacts and relation to workers performance or individual wellbeing be established. In this respect, the research tends to reflects on religiosity impact at the work settings in Ghana. 
Additionally, it reviews the theory that forms the basis of individual's attachment or bond to religion. In order for readers to appreciate and understand religion in the Ghanaian context, it provides a brief background about religion in Ghana. It further discuss psychological wellbeing and attempt to accentuate through literatures the relevance and impact of religiosity and psychological wellbeing to the individual and at the work setting. In this light, implications are explored and suggestions recommended at the individual and organization levels for policy makers, organizations, institutions and psychotherapy services to embed this recommendations for further development and progress of institutions and individuals.

\subsection{Religiosity impact at work settings in Ghana}

At the work settings, workers may develop sub-cultures determined by array of factors such as regular interactions, religious affiliations or affinities, common beliefs and practices shared by workers and other additionally factors employees may identify with. Individuals with moderate or strong religious faith may have their actions and attitudes at the work setting portraying underpinning values related to their religious beliefs, (Kutcher et al., 2010) because people bring their religious beliefs with them when they go to work. It should however be established that such informal behavior would be adopted simultaneously with the formal culture of the organization. Religion heavily permeates extensively in the organizational setting and culture in Ghana and some of its practices are embedded and recognized mostly formally and informally by some institutions. The evidence is echoed in most local organizations having organizational values and mission statements centered on values upheld in the sacred doctrines of religion it identifies with. The effect of emulating religious practices in an organization affirms Lambert (1997) who posited that whether people are religious or not, they are surrounded by its influence since it affects their environment. According to Kutcher et al (2010) religion and faith are often central aspects of an individual's self-concept, and yet they are typically avoided in the workplace.

Most organizations (both formal and informal) in Ghana has introduced a regular phenomenon of 'morning devotion' marked by praying and worship to reiterate their spiritual connectedness to a super mundane being prior to their daily tasks or activities for various reasons. However, the phenomenon is marked by enormous unidentified benefits impacting on workers psychological and mental wellbeing apart from the religious incentives in engaging in the practice. Individuals' perception about their capability, self-esteem, and recipe for personal interactions with others are reechoed and reemphasized in a positive and encouraging posture which tends to impact on individuals eventually affecting positively on the organization. Marri et al (2012) research indicates that Islamic work ethics has positive impact on job satisfaction and organizational commitment. Jansen, Motley, \& Hovey (2010) found that church attendance negatively correlated with anxiety and depression. Ivy (2014) investigated if religion affects workplace behavior, specifically organizational citizenship behavior (OCB). The result of the study concluded that religion with emphasis on internal religiosity dimension does have an effect on workplace behavior (OCB). Wening \& Choerudin (2015) investigated on education staffs (lecturers) of private and public universities in Yogyakarta, Indonesia. The results of the research revealed that religious behavior had an influence on the commitment of a college professor towards the organization. Karim, Bibi \& Aftab (2016) study results suggested religiosity fostered the effect of satisfaction with work-life balance on job satisfaction. The findings of these studies suggest that religiosity holds relevance to a variety of work outcomes. Faith and involvement in religious activities act as a personal resources, making individuals more resilient to cope with the challenges arising from work life imbalance. Hence, it can be established that it is essential to carry out further studies on essence of religious practices at the workplace.

\subsection{Brief History of Religion in Ghana}

Religion permeates most spheres of life around the world. However, it preoccupation, dominancy, practices and adoption varies from one location to another, defined by elements of culture and diverse ideological orientations. The profound influence of religion is acknowledge in political life, individual behavior, social and public life, work behavior and form the basis of most individual actions and response to situations. According to Kudaje and Aboagye-Mensah, "we are clear in our minds, that the church has a valid case to be involved in the affairs of the state in all aspects including national politics." The Constitution for instance makes provision for the inclusion of representation of religious groups in specific constitutional bodies. The Constitution for example provides in Article 166(1) for the representation of religious organizations on the National Media Commission in Ghana. There is freedom to practice and belong to any kind of religion without any form of restrictions. 
The core legislative basis for religious liberty is article 21(1)(c) of the 1992 Constitution which, similar to article 18 of the International Covenant on Civil and Political Rights (ICCPR), which guarantees the right of belief and the right to manifest. In the words of Rev. K. A. Dickson, Professor Emeritus and former President of the All African Conference of Churches, "generally speaking, freedom of religion is a reality in Ghana, as it is elsewhere in Africa, and this has led to unprecedented growth; attempts to restrict the Church's freedom have usually been resisted'. The constitution prohibits religious discrimination and stipulates individuals are free to profess and practice their religion (International Religious Freedom Report, 2015).

Although regulations and laws has been enacted both in the past and presently to regulate religious activities in the country but most enforcement programs has been less effective. While some contemporary policy agendas centering on religious activities has been on subject matters such as introduction of taxes on religious activities since it generates money, there are others that also hovers around establishing regulations to bring sanity into the practice due to numerous reports of abuses and human right infringements. There are limited regulations that control religious activities and any attempts to regulate its activities like any business ventures in Ghana may erupt fierce resistance from some practitioners.

Ghana is constitutionally regarded as a secular state. The National census data puts Christianity ahead of other religion in Ghana. Christianity is recognized as the dominant faith at 68.8 percent, Islam at 15.9 percent and traditional religion at 8.5 percent. The data further revealed that only 6.1 percent reported having no religious affiliations (Quarshigah).The rest are regarded as minor religions. Christian denominations include Roman Catholic, Methodist, Anglican, Mennonite, Evangelical Presbyterian, African Methodist Episcopal Zionist, Christian Methodist, Evangelical Lutheran, Eden Revival Church International, The Church of Jesus Christ of Latter-day Saints (Mormon), Seventh-day Adventist, Pentecostal, Baptist, African independent churches, the Society of Friends (Quaker), and numerous charismatic religious groups. Islamic traditions include Sunni, Ahmadiyya, the Tijaniyahand Qadiriyyaorders of Sufism, and a small number of Shia. (International Religious Freedom Report, 2015)

\subsection{Attachment Theory and Religious Bond}

Attachment theory is the cooperative work of John Bowlby and Mary Ainsworth (Ainsworth \& Bowlby, 1991).Attachment is a deep and enduring emotional bond that connects one person to another across time and space (Ainsworth, 1973; Bowlby, 1969).Granqvist, Mikulincer \& Shaver (2010) revealed that attachment theory was initially grounded in the observation that human beings appear to be born with an innate psychobiological system (the "attachment behavioral system") that motivates them to seek proximity to significant others (attachment figures).An affection bond forms in the typical caretaker-child relationship within the first several months of the child's life (Bowlby, 1979) that cannot entirely be accounted for as a result of the child's oral gratification when feeding at the breast (Ainsworth \& Bowlby, 1991). Attachment does not have to be reciprocal. One person may have an attachment to an individual which is not shared. Attachment is characterized by specific behaviors in children, such as seeking proximity to the attachment figure when upset or threatened (Bowlby, 1969).

Attachment behavior in adults towards the child includes appropriate and sensitive response to the child's wants. Such behavior exists across cultures. Attachment theory explains how the parent-child relationship emanates and affects further development. An affection bond forms in the typical caretaker-child relationship within the first several months of the child's life (Bowlby, 1979) that cannot entirely be accounted for as a result of the child's oral gratification when feeding at the breast (Ainsworth \& Bowlby, 1991).In the adolescence stage, the initial parental or caregiver attachment of early childhood is probable to be complemented or even displaced by new attachments, but in most cases the original attachment pattern will remain in existence for substantial period of time.Subsequent attachment to parental or caregiver attachment can be formed, for example, with a romantic partner, a close friend, a counselor, or even God (religious context) (Rowatt\& Kirk-Patrick, 2002). Attachment dynamics can be found in any religion that assumes a personal God (Kirkpatrick, 2005).The theory can be extended to explain the basis of the need and desire of individuals to extensively attach to a religion. Such religious attachment with a belief in a supreme deity figure represents a paternal and maternal figurative symbol of caring, empathetic relationship, and provider, security among providing other social and psychological needs and benefits. Individuals who fervently attached to a religious faith and beliefs have a high tendency to overcome and mitigate stressors in daily life that drain individual mentally and psychologically. 
Granqvist \& HagekuU (2003) concluded from their investigation that someone who had been insecurely attached and who had used religion to mitigate emotional distress may have moved to a more secure stance as a function of their new relationship with God or some reparative aspect of religiosity.

\subsection{Psychological Wellbeing}

Psychological well-being continue to be studied extensively as need grows to improve the state of mental conditions of people. There are enormous debilitating psychological and mental conditions that affect individuals' which necessitate desperate measures to address. Such mental state of individuals may have it rippling effects on organization and personal development. Tandon (2017) in his study revealed data from the National Health and Morbidity Survey conducted by the Ministry of Health in Malaysia in 2011. The report indicated a high level of mental health problems among Malaysian adults, with 0.3 million $(1.7 \%)$ of them experiencing anxiety disorders and having suicidal thoughts, another 0.3 million $(1.8 \%)$ of adults experiencing depression, and 0.2 million $(1.1 \%)$ having attempted suicide.

In simple terms, the concept of psychological well-being refers to how people evaluate their lives. According to Ryff et al. (1989), psychological well-being refers to the degree to which people feel and assume that they have significant control over their life's and their activities. According to Tandoh (2017) these evaluation may assume the form of cognitions or in the form of affect. There are numerous psychological and social factors that have been connected to increase individual life expectancy and quality of life in older adults.

Tandoh (2018) further revealed that researchers in the field of psychological wellbeing has come to a consensus that psychological wellbeing generally entails two important dimensions, namely positive and negative affect. As a result, both positive mental health (e.g. happiness and life satisfaction) and mental ill-health (e.g. anxiety and depression) are taken into account in the evaluation and measurement of psychological wellbeing. In this regard, Ryff (1989) presented six core dimensions of psychological well-being, namely: 1) self-acceptance (entails perception of state of individuals having positive thoughts and feelings about themselves); 2) positive relations with others (capacity to involve in warm, meaningful and trusting relationship with others); 3) autonomy (ability to be independent and coping with social pressure); 4) environmental mastery (capacity to adapt, alter or create one's environment according to one's needs through physical and mental activities); 5) purpose in life (state of having objectives and goals in life and working towards achieving goal-oriented); and 6) personal growth (continuous development of oneself to attain set goals).

\subsection{Religiosity and Psychological Wellbeing}

In contemporary times of rising political, economic and social instability, one may find it increasingly difficult to ward off feelings of anxiety, depression or loneliness (Reinberg, 2010).The link between religiosity and psychological wellbeing has been explored by researches although majority has come to a consensus on the positive link between these two variables. Studies on various dimensions of religiosity impact on dimensions of psychological wellbeing however disclose significant impact of religiosity on psychological wellbeing. William et al. (1991) highlights that a number of well conducted clinical and epidemiological studies have shown that the individuals with religiosity commitment had much less psychological distress than the uncommitted ones. From the assessment of Underwood \& Teresi (2002) religiosity plays a major role in the life of an individual. It can offer hope in despair times. In daily life, there are reports by individuals that they are able to experience deep peace even in the midst of mental distress.

Desmukh \& Ismail (2012) explored the link between religiosity and individual psychological wellbeing in a model of Pakistani Muslims. A strong positive relationship was found between religiosity and different facets of psychological wellbeing. Frazieret al. (2005) found a positive relationship between religiosity and psychological well-being. Similarly, other longitudinal studies revealed that regular religious attendance results in much less psychological distress and depression in different spheres of life (Joshi, Kumari \& Jain, 2008). Furthermore, other dimensional work by Leondari \& Gialiamas (2009) investigated the relationship between religiosity and psychological well-being. Church attendance, frequency of prayer and belief salience were religiosity dimension under consideration. In addition, depression, anxiety, loneliness, and general life satisfaction were selected as dimensions of psychological well-being. Analysis suggested that church attendance and belief salience were associated with better life satisfaction. Again, there was significant positive association between anxiety and frequency of personal prayer. Hays et al (2007) also in a study investigating the religion role on mental health discovered a positive relationship between frequency of prayers and health outcomes. 
Chime (2015) explored the relationship between religiosity and psychological well-being. It concluded that religious service attendance and obligatory prayers were associated with high level of self-esteem. Again, strong positive relationship was revealed between religious service attendance and psychological well-being.

The impact of religion and spirituality on mental health may be attributable to a combination of mechanisms such as increased social support, expanded psychological resources, positive health practice or a stronger sense of coherence (Helm et al, 2010). Pajevic, Sinanovic, and Hasanovic (2005) suggested that religiosity reduced psychopathological behaviors. Glass (2014) study results revealed that intrinsic religiosity was found to positively influence psychological well-being.

\subsection{Results and Discussion}

Religion serves as major device that permeates most spheres of life and it is evidenced in its recognition as fundamental for some national legislations, core business values and missions, business ethics, psychotherapy among others. According to Quarshigah, 'religion was always and is still, to a large extent, an integral part of the lifestyle of the African in the traditional environment'. Despite the recent attention from researchers, it has inadequately received the needed focus to extensively explore this interesting field of study.

Individuals who are moderately or strongly attached to a religious faith has a high tendency to form positive definition of self-concept, self-esteem and high capacity to ward off psychological and mental strains such as reducing psychopathological behaviors, and positively influencing psychological well-being. (Hasanovic, 2005; Glass, 2014) Again, it can be established through series of studies that the mechanisms by these individuals for coping with life stressors may be underpinned by values, inspirations, situational codes of behavior from their religious faith.

The effect of religiosity extends from the level of individuals to different environmentsor context such as work settings, policy making, in-group identification, determinants of certain group actions among others. In the arena of organizational settings in Ghana, religious beliefs and faith heavily penetrate the fabrics of most organizations. Most organizations integrate religious components of faith and practices into its organizational culture to be formally accepted by the organizational members such as regular devotional practice (praying and worship to a supernatural being- God). Core values and mission statements of most institutions are reflective of the principal values recognized in the sacred doctrines of this religion and tend to be appreciated and reciprocally upheld by its customers.

Contemporary social and work environment trapped individuals in vast number of stressors that individuals are challenged to deal with. This is affirmed by Reinberg (2010) who posited that in modern times of rising political, economic and social instability, one may find it increasingly difficult to ward off feelings of anxiety, depression or loneliness .Warding off anxiety, depression and other psychological strains to ensure psychological wellbeing requires individuals to be proactive to deal with such psychological problems. The review of numerous literatures indicates that religiosity and psychological wellbeing are substantial factors that have an effect at the individual level and also at organization level. It is therefore established that to ensure wellbeing of individuals or workers, religious participation or activities may be require to be set up and encouraged at various institutions since research has proven the benefits of continually engaging individuals. Workers can give off their best when they have the right psychological and mental frame. It is however recommended to institutions that are yet to adopt, embed or integrate these religious components of faith and practice as integral part of its organizational practices to embrace this culture. Again, other international and multinational organization can also emulate and embed this mechanism as part of its organizational culture because it empowers individuals to adapt and adjust to personal and work stress which guarantee psychological wellbeing of individuals.

It is imperative that institutions adopt this mechanism since the over reliance on structural adjustment, motivational schemes, organizational process and procedures in an organization does not always guarantee the success and progress of an organization. The influence of religion in an organization can be enormous as proposed by researches such as those linked to job satisfaction (Karim, Bibi \& Aftab, 2016 ;Marri et al ,2012), job commitment (Karim, Bibi \& Aftab (2016), high self-esteem (Chime, 2015), moderating work attitude (Kutcher et al., 2010) and recipe for employee - customer interaction. Additionally, Kutcher et al. (2010) study suggests that religiosity can be related to stress and burnout, organizational commitment, and organizational citizenship behavior.Again, there are implications for psychotherapy services to also incorporate aspect of religious faith and beliefs in its services in counseling therapies. 
As indicated by Bowlby (1979), attachment dynamics are typically activated when an individual is in distress, ill, or afraid. Moreover, the role of the therapeutic relationship is to offer a secure relationship for clients and to help them make adjustments and develop more coherent and healthy models of self and others (Shaver \& Clark, 1994). Attachment theory provides a framework which is considered more potent where counselors may conceptualize the religious experiences of clients whose spirituality involves the belief in a personal God (Reinert, Edwards \& Hendrix, 2009). These therefore provide clues and interventions to be adopted and employed in the psychotherapeutic process.

\section{References}

Ainsworth, M. D. S. (1973). The development of infant-mother attachment. In B. Cardwell \& H. Ricciuti (Eds.), Review of child development research. Chicago: University of Chicago Press, Vol. 3, pp. 1-94

Ainsworth, M. D. S., \& Bowlby, J. (1991). An ethological approach to personality development.

Bowlby J. (1969). Attachment. Attachment and loss: Vol. 1. Loss. New York: Basic Books.

Bowlby, J. (1979). The making and breaking of affectional bonds. London: Tavisto

Byrd, D.R., and K.J. McKinney (2012). Individual, interpersonal, and institutional level factors associated with the mental health of college students. Journal of American College Health, 60(3): 185-193.

Chime, E. (2015). A Study of Religiosity and Psychological Well-Being. Dissertation.

Frazier, C., Mintz, L. B., \& Mobley, M. (2005). A Multidimensional Look at Religious Involvement and Psychological Well-Being among Urban Elderly African Americans. Journal of Counseling Psychology, 52, 583- 590. doi: 10.1037/0022-0167 .52.4.583

Ghana 2015 International Religious Freedom Report. United States Department of State. Bureau of Democracy, Human Rights, and Labor.

Glass, N.Y. (2014). African American Women, Psychological Well-Being, Religiosity, and Stress(Dissertation). Kent State University College of Education, Health, and Human Services.

Granqvist, P., Mikulincer, M.,\& Shaver, P. R. (2010). Religion as attachment: Normative processes and individual differences. Personality and Social Psychology Review, 14. doi: 10.1177/1088868309348618

Helm, H., Hays, J. C., Flint, E., Koenig, H. G., \& Blazer, D. G. (2010). Effects of private religious activity on mortality of elderly disabled and nondisabled adults. Journal of Gerontology, 55A, M400-M405

Ismail, Z.,\& Desmukh, S. (2012). Religiosity and Psychological Wellbeing. International Journal of Business and Social Science. Vol. 3, No. 11

Ivy, J., S. (2014)"The Effects of Religion on Organizational Citizenship Behavior". Honors Theses. Paper 272

Jansen, K. L., Motley, R., \& Hovey, J. (2010). Anxiety, depression and students' religiosity. Mental Health, Religion and Culture, 13, 267-271. doi: 10.1080/ 13674670903352837

Joshi, S., Kumari, S., \& Jain, V. (2008). Religious Belief and its Relation to Psychological Well-being. Journal of the Indian Academy of Applied Psychology, Vol. 34, No. 2

Karim, J., Bibi, Z.,\& Faisal Aftab, F. (2016). The Moderating Role of Religiosity on the Relationship between Satisfaction with Work-Life Balance and Job Satisfaction. Journal of Business Studies Vol. 12, No. 1, 157-167

Kirkpatrick, L. (2005).Attachment, evolution, and the psychology of religion. New York: Guilfo

Kudajie, J., N.,\&Aboagye-Mensah, R., K. (1991). The Christian and National Politics, Vol. 1, Accra, Assempa Publishers, 1991, 33, quoted in Yirenkyi, id.

Kutcher, E. J., Bragger, J. D., Rodriguez-Srednicki, O., \& Masco, J. L. (2010). The Role of Religiosity in Stress, Job Attitudes, and Organizational Citizenship Behavior. Journal of Business Ethics, 95(2), 319-337.

Laird, R. D., Marks, L. D., \& Marrero, M. D. (2011). Religiosity, self-control, and antisocial behavior: Religiosity as a Promotive and Protective Factor. Journal of Applied Developmental Psychology, 32, 78-85. doi:10.1016/ j.appdev.2010.12.003

Lambert, F. (1997). 'God - and a religious president ... [or] Jefferson and no God': Campaigning for a VoterImposed Religious Test in 1800. Journal of Church and State, 39(4), 769-789. doi: 10. 1093/jcs/39.4.769

Leondari, A. \&Gialamas, V. (2009). Religiosity and psychological well-being. International Journal of Psychology. Vol. 44. Issue no 4. https://doi.org/10.1080/00207590701700529 
Marri M.Y.K., Sadozai A.M., Zaman H.M.F.,\&Ramay, M, .I. (2012). The impact of Islamic work ethics on job satisfaction and organizational commitment: a study of agriculture sector of Pakistan, "International Journal of Business and Behavioral Sciences", 2(12).

Pajevic, I., Sinanovic, O. \& Hasanovic, M. (2005).Religiosity and mental health. PsychiatriaDanubina, 17(1-2), 84-89.

Reinberg, S. (2010). Depression hits 9\% of adults, worst in South, CDC reports. USA Today online magazine.

Reinert, D. F., Edwards, E.C., \& Hendrix, R. R. (2009). Attachment Theory and Religiosity: A Summary of Empirical Research with Implications for Counseling Christian Clients.) Vol 53. Pp 112-125

Rowatt, W. C., \& Kirkpatrick, L. A. (2002). Two dimensions of attachment to God and their relation to affect, religiosity, and personality constructs. Journal for the Scientific Study ofReligion, 41,637-651.

Regehr, C., Glancy, D., \&Pitts, A. (2013). Interventions to reduce stress in university students: A review and meta-analysis. Journal of affective disorders, 2013, 148(1): 1-11.

Rev. K.A Dickson (2003). Freedom of Religion and the Church, Accra, Ghana Universities Press, 5.

Ryff, C.D. (1989) Happiness is everything, or is it? Explorations on the meaning of psychological well-being. Journal of Personality and Social Psychology, 1989, 57(6): 1069-81

Shaver, P. R., \& Clark, C. L. (1994). The psychodynamics of adult romantic attachment. In J. M. Masling\& R. F. Borstein (Eds.), Empirical perspectives on object relations theory (pp. 105-156). Washington, DC: American Psychological Association

Sherina, M., Rampal,L., \& N. Kaneson, N. (2014). Psychological stress among undergraduate medical students. Medical Journal of Malaysia, 59(2): 207-211.

Tandon, M (2017). A study of Psychological Wellbeing among elderly. International Journal of Home Science. 3(1): 387-389

Underwood, C. G.,\& Teresi, J. (2002). The daily spiritual experience scale: Development, theoretical description, reliability exploratory factor analysis and preliminary construct.

Weber, A., J (2012).Effects of Religiosity on Psychological Well-Being. Indiana University South Bend Undergraduate Research Journal. Vol. 12.

Wening, N.,\& Choerudin A. (2015). The Influence of Religiosity towards Organizational Commitment, Job Satisfaction and Personal Performance. Polish Journal of Management Studies. Vol.11, No2

Williams, R. W., Larson, D. B., Bukler, R. E., Heckman. R. C., \& Pyle, C. M. (1991).Religion and psychological distress in a community sample. Social Science Medicine, 32, 1257-1262.

Quashigah, K. Faculty of Law. University of Ghana. 